\title{
Construction of a comparative genetic map in faba bean (Vicia faba L.); conservation of genome structure with Lens culinaris Simon R Ellwood*1, Huyen TT Phan ${ }^{1}$, Megan Jordan ${ }^{1}$, James Hane ${ }^{1}$, Anna M Torres ${ }^{2}$, Carmen M Avila ${ }^{2}$, Serafín Cruz-Izquierdo ${ }^{2}$ and Richard P Oliver ${ }^{1}$
}

Address: ${ }^{1}$ Australian Centre for Necrotrophic Fungal Pathogens, State Agricultural Biotechnology Centre, Health Sciences, Murdoch University 6150, Western Australia and 2IFAPA, Centro Alameda del Obispo, Area de Mejora y Biotecnología, Apdo. 3092, E-14080 Córdoba, Spain

Email: Simon R Ellwood* - s.ellwood@murdoch.edu.au; Huyen TT Phan - h.phan@murdoch.edu.au; Megan Jordan - megan_jordan83@yahoo.com.au; James Hane - j.hane@murdoch.edu.au; Anna M Torres - anam.torres.romero@juntadeandalucia.es ; Carmen M Avila - carmen.avila.ext@juntadeandalucia.es; Serafín CruzIzquierdo - serafin.cruz.ext@juntadeandalucia.es; Richard P Oliver - r.oliver@murdoch.edu.au

* Corresponding author

Published: 9 August 2008

BMC Genomics 2008, 9:380 doi:10.1 186/1471-2164-9-380
Received: 18 March 2008

Accepted: 9 August 2008

This article is available from: http://www.biomedcentral.com//47I-2/64/9/380

(c) 2008 Ellwood et al; licensee BioMed Central Ltd.

This is an Open Access article distributed under the terms of the Creative Commons Attribution License (http://creativecommons.org/licenses/by/2.0), which permits unrestricted use, distribution, and reproduction in any medium, provided the original work is properly cited.

\begin{abstract}
Background: The development of genetic markers is complex and costly in species with little preexisting genomic information. Faba bean possesses one of the largest and least studied genomes among cultivated crop plants and no gene-based genetic maps exist. Gene-based orthologous markers allow chromosomal regions and levels of synteny to be characterised between species, reveal phylogenetic relationships and chromosomal evolution, and enable targeted identification of markers for crop breeding. In this study orthologous codominant cross-species markers have been deployed to produce the first exclusively gene-based genetic linkage map of faba bean (Vicia faba), using an $F_{6}$ population developed from a cross between the lines $V f 6$ (equina type) and Vf27 (paucijuga type).
\end{abstract}

Results: Of 796 intron-targeted amplified polymorphic (ITAP) markers screened, I5I markers could be used to construct a comparative genetic map. Linkage analysis revealed seven major and five small linkage groups (LGs), one pair and 12 unlinked markers. Each LG was comprised of three to 30 markers and varied in length from $23.6 \mathrm{cM}$ to $324.8 \mathrm{cM}$. The map spanned a total length of $1685.8 \mathrm{cM}$. A simple and direct macrosyntenic relationship between faba bean and Medicago truncatula was evident, while faba bean and lentil shared a common rearrangement relative to $M$. truncatula. One hundred and four of the 127 mapped markers in the 12 LGs, which were previously assigned to $M$. truncatula genetic and physical maps, were found in regions syntenic between the faba bean and $M$. truncatula genomes. However chromosomal rearrangements were observed that could explain the difference in chromosome numbers between these three legume species. These rearrangements suggested high conservation of $M$. truncatula chromosomes I, 5 and 8; moderate conservation of chromosomes 2, 3, 4 and 7 and no conservation with $M$. truncatula chromosome 6. Multiple PCR amplicons and comparative mapping were suggestive of small-scale duplication events in faba bean. This study also provides a preliminary indication for finer scale macrosynteny between $M$. truncatula, lentil and faba bean. Markers originally designed from genes on the same $M$. 
truncatula BACs were found to be grouped together in corresponding syntenic areas in lentil and faba bean.

Conclusion: Despite the large size of the faba bean genome, comparative mapping did not reveal evidence for polyploidisation, segmental duplication, or significant rearrangements compared to $M$. truncatula, although a bias in the use of single locus markers may have limited the detection of duplications. Non-coding repetitive DNA or transposable element content provides a possible explanation for the difference in genome sizes. Similar patterns of rearrangements in faba bean and lentil compared to $M$. truncatula support phylogenetic studies dividing these species into the tribes Viceae and Trifoliae. However, substantial macrosynteny was apparent between faba bean and $M$. truncatula, with the exception of chromosome 6 where no orthologous markers were found, confirming previous investigations suggesting chromosome 6 is atypical. The composite map, anchored with orthologous markers mapped in $M$. truncatula, provides a central reference map for future use of genomic and genetic information in faba bean genetic analysis and breeding.

\section{Background}

Faba bean (Vicia faba L.) is currently the third most important cool-season food legume in the world. Faba bean provides an important source of dietary protein in human diet, edible oil and animal feeds. Like other grain legumes, faba bean contributes to sustainable agriculture in the management of soil fertility and plays an essential role in crop rotation. Faba bean is a diploid with $2 \mathrm{n}=2 \mathrm{x}=12$ chromosomes $[1,2]$, is partially cross-pollinated ranging from 4 to $84 \%$ [3], and possesses one of the largest genomes among crop legumes ( 13000 Mb). The development of saturated linkage maps as well as the identification and map-based isolation of important qualitative traits or quantitative trait loci is therefore complex and expensive.

A saturated genetic linkage map provides an invaluable tool in plant genetic studies and practical breeding. One of the first genetic linkage maps of faba bean was constructed by Van de Ven et al. [4] with only 17 markers; followed by successively more detailed genetic maps by Torres et al. [5] with 51 markers, Satovic et al. [6] with 157 markers, Vaz Patto et al. [7] with 116 markers, Roman et al. [8] with 121 markers, Roman et al. [9] with 192 markers and Avila et al. [10] with 103 markers. To date, faba bean genetic maps have been restricted to morphological, isozyme, RFLP, RAPD, a few seed protein genes and four SSR markers. These markers have been limited either in number, transferability or in their ability to provide syntenic information with other legume species.

The recent generation of abundant genomic and genetic resources focussed around the model species Medicago truncatula and Lotus Japonicus has opened up abundant opportunities for creating gene-based molecular markers that are ideal for genetic mapping in general and comparative mapping in particular [11-16]. In this approach, oligonucleotide primers were designed from sequences of conserved regions in gene exons that flank polymorphic regions such as introns or microsatellites. This PCR-based, codominant marker system has remarkably increased the efficiency of transferring genetic information across species. Examples include the comparison of $M$. truncatula with alfalfa, pea, chickpea, soybean, mung bean, lentil and lupins [12-18].

Comparative genomic studies can expose and confirm phylogenetic relationships among species and determine patterns of chromosomal evolution and syntenic relationships. More importantly, comprehensive comparative genomics can facilitate back-and-forth use of genomic resources between different legumes species, and help to reduce cost and increase efficiency in genetic research as well as crop breeding. The use of conserved genome structure to assist in transferring knowledge among related plant species is well established in grasses $[19,20]$ where synteny greatly assists in gene identification among related species.

In this paper we report: (1) the application of gene-based markers in faba bean; (2) the development of the first exclusively gene-based genetic and comparative map for the species; (3) analysis of syntenic relationship between faba bean and M. truncatula; and (4) the levels of homology existing between faba bean, $M$. truncatula and lentil, a closely related species to faba bean.

\section{Methods \\ Genetic mapping population}

A gene-based genetic map of faba bean genome was constructed using a population of $94 \mathrm{~F}_{6}$ RILs generated from a cross between faba bean line Vf6 (equina type) as the pollen recipient and line Vf27 as pollen donor (paucijuga type). These accessions have been widely used in previous genetic studies $[7,9,21]$ and the population was developed at IFAPA, Centro Alameda del Obispo, in Córdoba, 
Spain, using diploid parental individuals. Total genomic DNA was isolated from each parent and $\mathrm{F}_{6}$ individual as previously described [22].

\section{Primer design}

A total of 796 intron-targeted amplified polymorphic markers (ITAPs) were used for this study. These were composed of four sets of ITAPs; $340 \mathrm{ML}$ and Lup primers developed from alignment of M. truncatula and Lupinus spp. database EST sequences; 160 MLG primers based on alignments between M. truncatula, Lupinus albus, and Glycine max ([15], with a subset of these denoted AtMtL-); 143 cross-species makers (MP) developed by the Department of Plant Pathology, University of California, Davis, USA [12]; and 140 GLIP markers created by the European Grain Legumes Integrated Project (GLIP) based on primarily on M. truncatula and pea (Andrea Seres, pers. comm.). The majority of the ITAPs markers could be positioned to a physical location in the $M$. truncatula psuedogenome since most primers were designed from genes in characterized chromosomal regions.

\section{Polymorphism detection}

Each primer pair was screened on $V$. faba parental DNA. PCR conditions were optimised to produce clear single amplicons, and single PCR products of the same size were purified and directly sequenced. Different detection methods were used to genotype the $\mathrm{F}_{6}$ population dependent on the type of polymorphism [15]. Details of each marker are given in Additional file 1.

\section{Map construction}

Chi-squared analysis $(\mathrm{P}<0.05)$ was applied to test the segregation of the mapped markers against the expected Mendelian segregation ratio for co-dominant inheritance in the faba bean $\mathrm{F}_{6}$ RIL population. Genetic linkage mapping was conducted with MultiPoint v 1.2 software [23], with a recombination fraction $(\mathrm{rf})$ of $0.29(\mathrm{LOD}=9.0)$ using 5000 bootstraps. Map distances were calculated in cM by applying the "Kosambi" function. Groups of linked markers that were similarly distorted were accepted for linkage mapping. Independent markers showing signifi- cant segregation distortion and markers with missing data ( $>10 \%$ ) were rejected for linkage to avoid bias and false linkages. Genetic maps were drawn with the software program MapChart v 2.1 [24].

\section{Establishment of macrosyntenic relationships between faba bean, lentil and $M$. truncatula}

Markers mapped in faba bean were located on the M. truncatula map by aligning the ESTs originally used to design the ITAPs primers with M. truncatula BACs in the Medicago pseudogenome Mt2.0 build 8/10/2007. Alignments with a BLAST $E$ values $<1 e^{-20}$, hsp identity $\geq 60 \%$, and hsp length $>50 \mathrm{nt}$ were retained. Precise positions of markers were obtained by aligning the ITAP primer sequences with M. truncatula BACs using BLASTN with an expected value $<1 \mathrm{e}^{-4}$ (primer length varied from $18 \mathrm{bp}$ to $28 \mathrm{bp}$ ). Approximate positions of markers that had been genetically mapped in M. truncatula but not yet positioned on the physical map were obtained from the $M$. truncatula genetic map [25].

\section{Loci dot plot created via Grid Map}

Grid Map [26] was used to compare the genetic maps of faba bean and M. truncatula. Ordered loci from faba bean and $M$. truncatula linkage groups were listed vertically and horizontally, respectively, and dots were positioned on the diagram at the intersection of the locations of the corresponding markers in the two genetic maps.

\section{Results}

\section{Gene-based marker development}

Of the 796 markers screened for amplification in genomic faba bean DNA, 19\% produced two or more amplicons of different sizes. Five hundred and seven were selected and optimised for single-locus amplification. Fifty percent (254) of these produced clear single band amplicons (Table 1). Seven markers that produced two amplicons (AIGP, GLIP172, GLIP429, GLIP621, GLIP651, Lup226 and MMK1) and one that produced three amplicons (LG34) were also mapped as they exhibited convenient length polymorphisms. One hundred and sixty-five polymorphic markers were identified (Table 1), of which 151

Table I: Efficiency of gene-based markers used to construct the comparative genetic linkage map of faba bean

\begin{tabular}{lllcccc}
\hline Marker type & Screened & Amplification & Length polymorphism & Sequenced & CAPS/SNPc & Mapped \\
\hline MP & 143 & $120(84 \%)$ & 6 & $75(63 \%)$ & $45(60 \%)$ & 36 \\
ML & 340 & $115(34 \%)$ & 9 & $30(26 \%)$ & $16(53 \%)$ & 25 \\
MLG & 160 & $132(83 \%)$ & 5 & $73(55 \%)$ & $50(70 \%)$ & 42 \\
GLIP & 140 & 140 & 6 & $76(54 \%)$ & $54(71 \%)$ & 48 \\
\hline Total & 796 & 507 & 26 & 254 & 165 & 151 \\
\hline
\end{tabular}

aFigures in parentheses are percentages of amplified markers of the total markers screened.

bFigures in parentheses are percentages of sequenced markers of the total amplified markers.

cFigures in parentheses are percentages of polymorphic markers of the total sequenced markers. 
markers were used to genotype the 94 individuals of the $\mathrm{F}_{6}$ RIL population (supplementary Table 1). Apart from the GLIP markers which were selected for their ability to amplify faba bean genomic DNA before this study, 'MLG' and 'MP' markers worked equally well in faba bean ( $83 \%$ and $84 \%$, respectively) but 'MP' markers produced fewer polymorphic amplicons. Amplification rate of the 'ML' markers was the poorest (34\%), less than half the rate of the 'MLG' and 'MP' groups (Table 1). Likewise, the polymorphism level of the 'ML' markers was the lowest. Both 'MLG' and 'GLIP' markers produced very high levels of polymorphism in the mapping parents $(70 \%$; Table 1$)$. DNA sequences of markers have been submitted to Genbank under accession codes $\underline{\text { FH893713 - FH937528. }}$.

Nineteen mapped markers ( $>12 \%)$ deviated significantly $(\mathrm{P}<0.05)$ from the expected Mendelian inheritance ratio of $1: 1$. About half of these markers (9) were highly distorted $(\mathrm{P}<0.01)$. Fifty percent of the distorted markers segregated in favour of the Vf6 parent and fifty percent in favour of Vf27. Nine of the 12 faba bean LGs contained one to four of these distorted markers, which tended to be scattered throughout the faba bean genome. However, it is noteworthy that distorted markers grouped together in chromosomes FB-1, 7 and 8 (Figure 1).

\section{The first gene-based and comparative map of Faba bean}

A total of 151 genic markers were used to generate the first gene-based and comparative map of faba bean. This map was constructed with a recombination fraction of 0.29 $[\mathrm{LOD}=9.0,27]$. The map consists of seven main linkage groups (FB-1 to FB-7) and 5 fragments (FB-8 to FB-12), which varied in length from 23.6 to $324.8 \mathrm{cM}$, and spans a total of nearly $1686 \mathrm{cM}$ (Figure 1 and Table 2). The number of markers per LG ranged from three to 30 markers. In addition, there was one pair and thirteen unlinked markers. Eight markers co-segregated at four loci, (three loci in FB-1, one in FB-3; Figure 1 and Table 2). The maximum distances between markers ranged from $13.8 \mathrm{cM}$ in FB-12 to $40.2 \mathrm{cM}$ in FB-3 with an overall mean gap distance of $14.6 \mathrm{cM}$ (Table 2).

Of the 135 genic markers that mapped to the 12 faba bean LGs in Figure 1, 127 were assigned to the M. truncatula genetic or physical maps [25]. One hundred and four of these $(82 \%)$ were in syntenic regions. Clear evidence of a simple and direct macrosyntenic relationship between the $V$. faba and M. truncatula is presented in the dot matrix in Figure 2. The formation of clear isoclinic diagonal lines along the linkage groups provides a strong indication of the conservation of gene order in the two legume genomes. The extensive colinearity was particularly prevailing between FB LG 1, 2, 3, 4 and Mt LG 8, 1, 4, 5 where syntenic regions accounted for $90 \%, 86 \%, 50 \%$ and $47 \%$ of the M. truncatula pseudogenome, respectively (Table 3).

However, chromosomal rearrangements were also evident at a moderate level. For example, $M$. truncatula chromosomes 1 and 7 together with 5 and 2 merged to form the faba bean LGs 2 and 4, respectively. Similarly, M. truncatula chromosome 2 splits into FB- 4 and 8 and M. truncatula chromosome 3 into FB-5 and 9 (Table 3 and Figure 2). Inversions and translocations were also notable among the orthologous markers within each syntenic pair of faba bean and M. truncatula LGs (Figure 2).

\section{Evidence of macrosynteny among faba bean, lentil and Medicago truncatula}

A high level of co-linearity was found between the faba bean, lentil and $M$. truncatula genomes based on the macro-synteny established between faba bean and $M$. truncatula (this study) or lentil and M. truncatula [15] using only common orthologous markers which mapped in all three species (Figures 3 and 4). The pattern of homology between faba bean and $M$. truncatula was similar to that between lentil and M. truncatula: for example, two linkage groups FB-1 and Len-II were exclusively syntenic to $M$. truncatula LG_8 and shared seven markers in common. Common markers were evenly distributed in all the three corresponding LGs suggesting that FB-1 and LenII are essentially co-linear (Figure 3A). Likewise, FB-2 and Len-III were both syntenic to Mt-1 and orthologous to each other with nine markers in common (Figure 3B). Other examples are FB-3, Len-I and Mt-4; and FB-4, Len-V and Mt-5 (Figure 2, 4A and Phan et al., 2007 [15]). FB-5 and FB-9 were co-linear with lentil Len-VII and LenVI, respectively, and both pairs of these linkage groups were colinear with Mt-3 (Figure 4B). This suggests shared ancestral chromosomal changes in faba bean and lentil compared to M. truncatula and confirms their phylogenetically closer relationship.

\section{Evidence of fine scale macrosynteny on individual BACs between faba bean, lentil and Medicago truncatula} Several ITAP markers used in this study were designed from different genes on the same M. truncatula BACs. These markers often mapped in clusters in two or more species and in common syntenic regions of corresponding linkage groups. An example is shown in Figure 3A with markers LG89-LG98 designed from M. truncatula BAC AC140032 and LG83-LG88 from M. truncatula BAC AC138131 in M. truncatula chromosome 8. Similarly, with the exception of LG34c, markers LG31-LG43 designed from M. truncatula BAC AC152751 in Mt chromosome 1 were located in one area of FB-2 and Len-III as shown in Figure 3B; markers AnMtL6-AnMtL8 and LG102-LG112 from M. truncatula BAC AC147712 and AC135800 in Mt chromosome 3 were grouped together 
$\begin{array}{lllllll}\text { FB-1 } & \text { FB-2 } & \text { FB-3 } & \text { FB-4 } & \text { FB-5 } & \text { FB-6 } & \text { FB-7 }\end{array}$

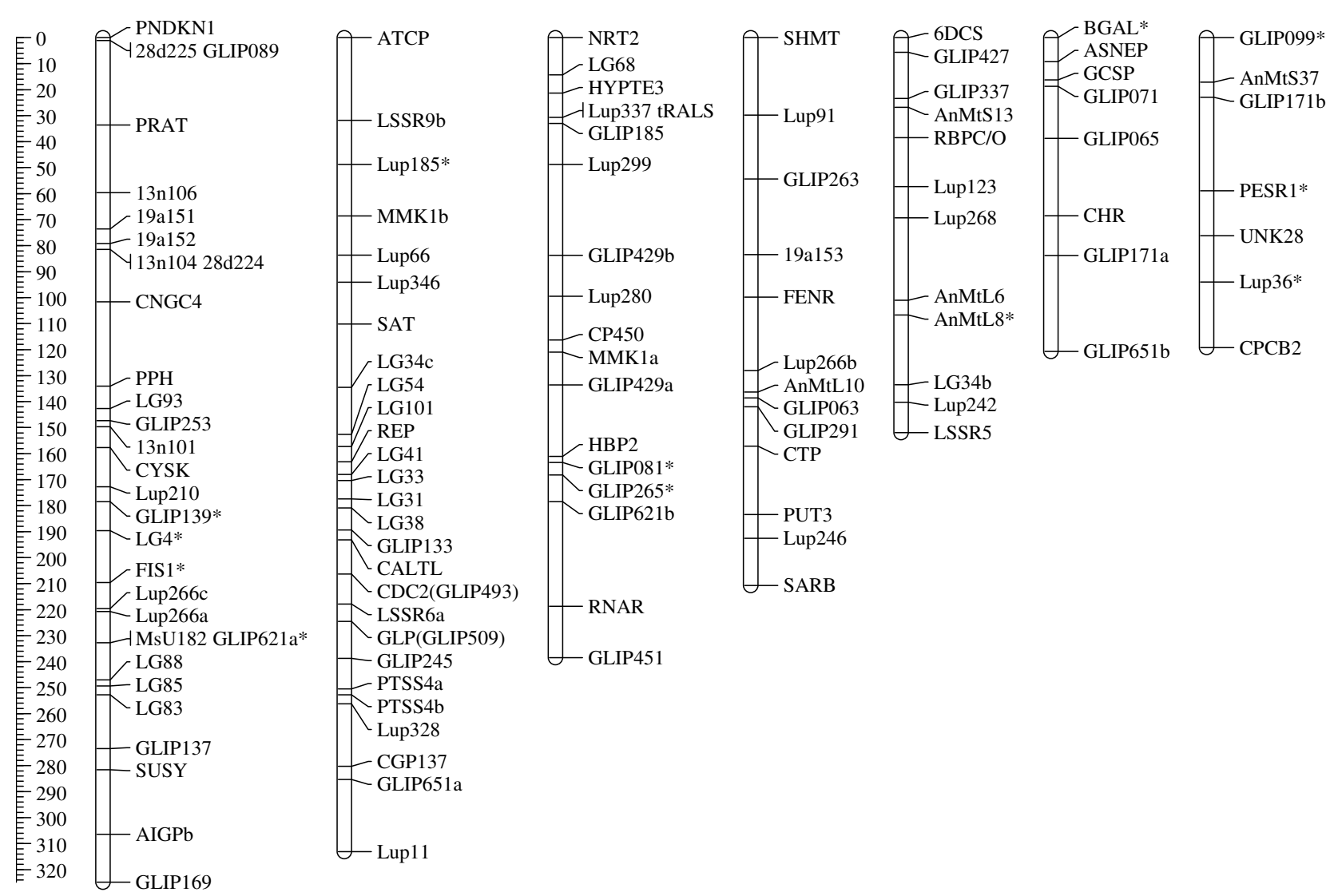

\section{FB-8 FB-9 FB-10 FB-11 FB-12}

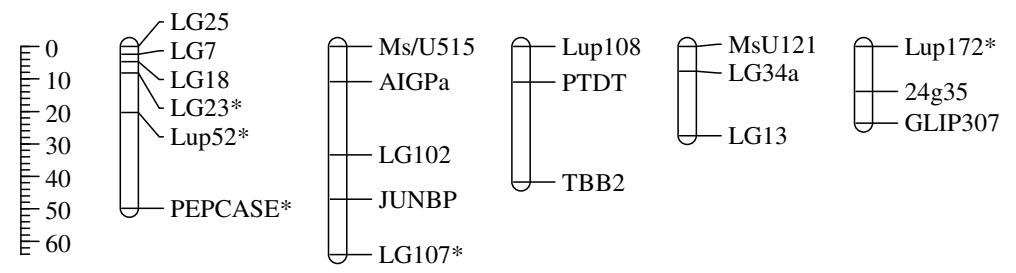

Figure I

A gene-based genetic linkage map of faba bean (Vicia faba L). Marker distance is given in cM. *indicates markers with distorted segregation.

on corresponding pairs of LGs i.e. FB-5 and Len-VII and FB-9 and Len-VI; respectively (Figure 4B).

\section{Discussion and conclusion}

The first genetic map of faba bean composed exclusively with gene-based co-dominant molecular markers was constructed using a $\mathrm{F}_{6}$ RIL population between lines Vf6 and Vf27. The map is also the first to enable the establishment of syntenic relationships between faba bean and the model legume $M$. truncatula, comparison with other legume species, and integration with genetic maps available in faba bean. 
Table 2: Properties of the faba bean comparative map

\begin{tabular}{cccccc}
\hline Linkage group & Length of LGs (cM) & No of markers & No of loci & Average marker spacinga (cM) & Largest distance between markers (cM) \\
\hline LG-1 & 324.8 & 30 & 27 & 12.5 & 32.5 \\
LG-2 & 313.1 & 27 & 27 & 12.0 & 31.8 \\
LG-3 & 238.5 & 18 & 17 & 14.9 & 40.2 \\
LG-4 & 210.7 & 13 & 13 & 17.6 & 29.8 \\
LG-5 & 151.9 & 12 & 12 & 13.8 & 26.8 \\
LG-6 & 120.7 & 8 & 8 & 17.2 & 36.9 \\
LG-7 & 119.2 & 7 & 7 & 19.9 & 35.9 \\
LG-8 & 49.9 & 6 & 6 & 10.0 & 29.5 \\
LG-9 & 64.1 & 5 & 5 & 16.0 & 22.6 \\
LG-10 & 41.8 & 3 & 3 & 15.4 & 30.7 \\
LG-II & 27.5 & 3 & 3 & 11.8 & 19.9 \\
LGI2 & 23.6 & 3 & 131 & & 13.8 \\
\hline
\end{tabular}

${ }^{a}$ Calculated by dividing the length of the chromosome (cM) by the number of space/distance between markers/loci.

The map is composed of 12 linkage groups and 151 genetic markers. Although the number of chromosomes in faba bean has been reported as $2 n=12$ [2], the number of linkage groups in recent genetic maps in the species range from 13 to 18 [7-10] and previously as many as 48 have been reported [6]. The high number of linkage groups compared to the number of chromosomes may be due to the fact that faba bean possesses one of the largest genomes among cultivated legumes ( 13000 Mb). This

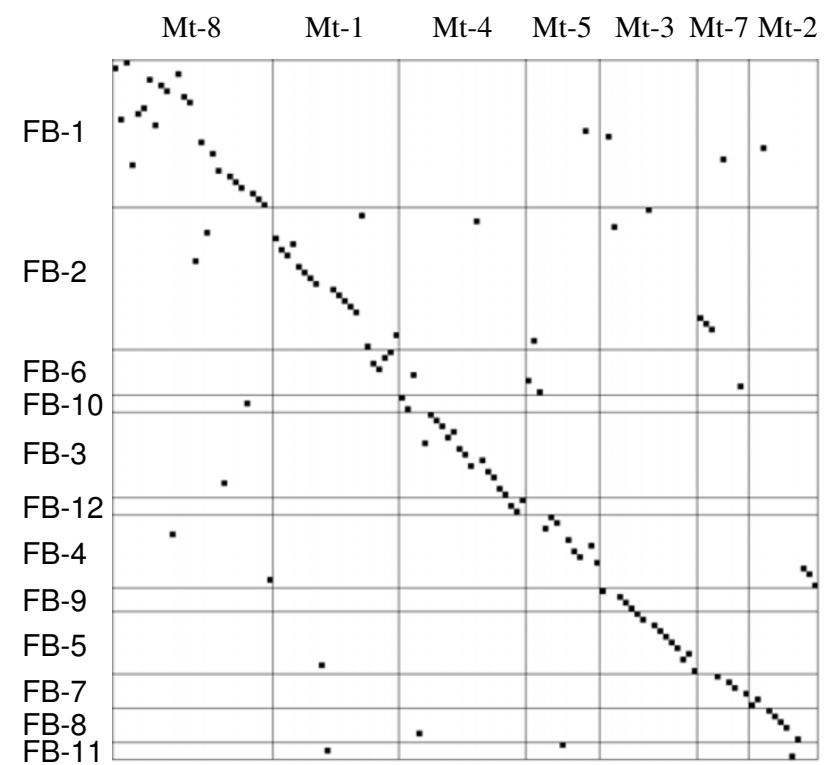

\section{Figure 2}

Matrix plot of common gene-based markers mapped in faba bean and $M$. truncatula. The faba bean and $M$. truncatula loci are listed vertically and horizontally, respectively, according to their linkage group order. compares with other well-characterised species such as $M$. truncatula, chickpea, soybean, lentil and pea which have genomes of $\sim 450 \mathrm{Mb}, \sim 740 \mathrm{Mb}, \sim 1200 \mathrm{Mb}, \sim 4000 \mathrm{Mb}$ and $\sim 4000 \mathrm{Mb}$ respectively [28].

Of the 24 non-orthologous markers found in this study, eight were from primer pairs where more than one PCR gel band was present and where two or more such amplicons were mapped. In each case, at least one amplicon mapped syntenically. The percentages of markers sequenced in faba bean were lower compared to lentil (63\%, $26 \%$ and $55 \%$ compared to $93 \%, 69 \%$ and $65 \%$ for MP, ML and MLG markers respectively, Table 1). This was due to higher proportion of markers amplifying multiple bands in faba bean compared to lentil (data not shown), which may imply duplication. Differences in amplification, sequencing and polymorphism rates among different types of markers used for this study reflect the mode of design of the markers. Since 'MP' and 'MLG' markers were often based on the homology of more than two phylogenetically distant species, they are more likely to work in different legume lineages. The same observation was reported for these primer sets in lentil [15].

Despite the large differences in genome sizes between $M$. truncatula and $V$. faba, a simple and direct relationship between the two genomes was identified in this study. Given the number of markers used (151), the syntenic regions cover a large proportion of $M$. truncatula pseudogenome with $90 \%, 87 \%, 66 \%, 62 \%$ and $47 \%$ for M. truncatula chromosomes 8, 1, 3, 4 and 5, respectively (Table 3 ). The appearance of clear isoclinic diagonal lines along the linkage groups in Figure 2 also demonstrates strong evidence for the extensive co-linearity between linkage group pairs of the two species. Similar high levels of conservation have also been reported between $L$. culinaris ssp. 
Table 3: Colinearity between the faba bean and $M$. truncatula genomes

\begin{tabular}{|c|c|c|c|c|c|c|}
\hline FB LG & No. of markers & $\begin{array}{l}\text { No. of non- } \\
\text { orthologous } \\
\text { markers }\end{array}$ & $\begin{array}{l}\text { No. of unassigned } \\
\text { markers }\end{array}$ & $\begin{array}{l}\text { Current Mt genetic } \\
\text { coverage (LG: cM, No. } \\
\text { colinear markers) })^{1,2}\end{array}$ & $\begin{array}{l}\text { Current Mt } \\
\text { pseudogenome } \\
\text { coverage (bp) }\end{array}$ & $\begin{array}{l}\text { Current faba bean } \\
\text { genetic coverage } \\
(\mathrm{cM})^{2}\end{array}$ \\
\hline FB-I & 30 & 6 & 2 & $8: 0-68.2,11$ & $\begin{array}{l}8: 736241-32433863 \\
(90 \%)\end{array}$ & $0-324.8(100 \%)$ \\
\hline FB-2 & 27 & 4 & 2 & $\begin{array}{l}1: 0-58.5,97: 58.4- \\
60,3\end{array}$ & $\begin{array}{l}\text { I: } 59849-26963044 \\
(86 \%) 7: 257259 \mid 8- \\
26383 \mid 68(2 \%)\end{array}$ & $\begin{array}{l}|52.6-3| 3 . \mid(5 \mid .3 \%) \\
|57 .|-2 \mid 0.7(25.4 \%)\end{array}$ \\
\hline FB-3 & 18 & 1 & 3 & $4: 48.1-59,11$ & $\begin{array}{l}4:|454483|- \\
34 \mid 28326(50 \%)\end{array}$ & $0-238.5(100 \%)$ \\
\hline FB-4 & 13 & 2 & 0 & $\begin{array}{l}5: 0-32,62: 12.7- \\
37.9,3\end{array}$ & $\begin{array}{l}\text { 5: } 594897-17960204 \\
(47 \%) 2: 8491236- \\
\text { 1520167| (24\%) }\end{array}$ & $\begin{array}{l}0-142(67 \%) 250.5- \\
256.3(1.9 \%)\end{array}$ \\
\hline FB-5 & 12 & 1 & 1 & $3: 28-70.3,9$ & $\begin{array}{l}\text { 3: }|0888| 4 \mid- \\
282 \mid 3807(46 \%)\end{array}$ & $0-140.3(92 \%)$ \\
\hline FB6 & 8 & 4 & 0 & $\mathrm{I}: 2-2.2, \mathrm{NA}$ & $\begin{array}{l}\text { I: } 4942324-5151182 \\
(0.7 \%)\end{array}$ & - \\
\hline FB-7 & 7 & 0 & 0 & $7: 22.6-52.8,4$ & $\begin{array}{l}\text { 7: } 9999559-22150020 \\
(38 \%)\end{array}$ & $0-58.9(49 \%)$ \\
\hline FB-8 & 6 & 1 & 0 & $2: 48-57.8,5$ & $\begin{array}{l}\text { 2: } 17523205- \\
20646361(11 \%)\end{array}$ & $0-49.9(100 \%)$ \\
\hline FB-9 & 5 & 0 & 0 & $3: 62-72.5,5$ & $\begin{array}{l}\text { 3: } 19000000^{*}- \\
307 \mid 2150(31 \%)\end{array}$ & $0-64.1(100 \%)$ \\
\hline FB- 10 & 3 & 1 & 0 & $4: 0-7.4, \mathrm{NA}$ & $\begin{array}{l}\text { 4: } 537530-3489843 \\
(8 \%)\end{array}$ & - \\
\hline FB-II & 3 & 3 & 0 & NA & NA & - \\
\hline FB- 12 & 3 & 0 & 0 & $4: 60.4-61.1, \mathrm{NA}$ & $\begin{array}{l}4: 36664007- \\
38|8608|(4 \%)\end{array}$ & - \\
\hline
\end{tabular}

NA: not applicable

IData was either based on information from M. truncatula genome sequencing website [25] or from Choi et al. [12].

${ }^{2}$ Data is provided for three or more colinear markers and excludes markers on the same chromosome rearranged relative to the order in $M$. truncatula.

culinaris and M. truncatula [15] and other closely related legumes such as $L$. culinaris ssp. culinaris and $P$. sativum [29], M. sativa and P. sativum [30], M. truncatula and $P$. sativum [17], M. truncatula and M. sativa [11]. This study also shows markers originally designed from genes on the same BAC clustered in corresponding syntenic areas in lentil and faba bean. The mapping populations were too small to resolve marker order in lentil and faba bean but extensive conservation of gene order,(and microsynteny) has been shown in previous studies between other legume species at similar or greater phylogenetic distances [12,3134], and to some extent between M. truncatula and Arabidopsis [33-35].

A higher level of homology between $V$. faba and L. culinaris ssp. culinaris compared to that between $V$. faba and M. truncatula could be inferred from this study based on the common markers mapped in the two genomes, common homology with M. truncatula and similar pattern of rearrangements (Figures 3, 4 and Phan et al., 2007 [15]). This finding agrees with phylogenetic studies that place the genera Vicia, Lens and Pisum within the tribe Viceae while Medicago and Melilotus form a parallel tribe Trifolieae within the Galegoid or cool season legumes [36], and is consistent with different levels of macrosynteny observed between M. truncatula, P. sativum, V. radiata, G. max, and Phaceolus vulgaris dependent on phylogenetic distance [12]. However, chromosomal rearrangements were evident (Figures 2 and 3 ).

Rearrangements involving Mt 6 and Mt3 in particular may explain the differences in chromosome number between the two species (M. truncatula: $\mathrm{n}=8 ; V$. faba: $\mathrm{n}=6$ ). Mt6 might be considered unusual and is largely composed of heterochromatic DNA [37], contains few transcribed genes [11] and a large proportion of resistance gene analogues [38]. In this study no corresponding linkage group was detected in faba bean, as found previously in pea [12] and lupin $[13,14]$, together with less than five percent estimated coverage by the L. japonicus genome [34]. In faba bean FB5 and FB9 appear to correspond to Mt3. This configuration is supported by a similar pattern in lentil (Figure 4B and Phan et al., 2007 [15]), although a larger number of markers are needed to confirm this.

The faba bean comparative map constructed here is consistent with the pattern of chromosome conservation previously observed, where different levels of conservation 
A

FB-1

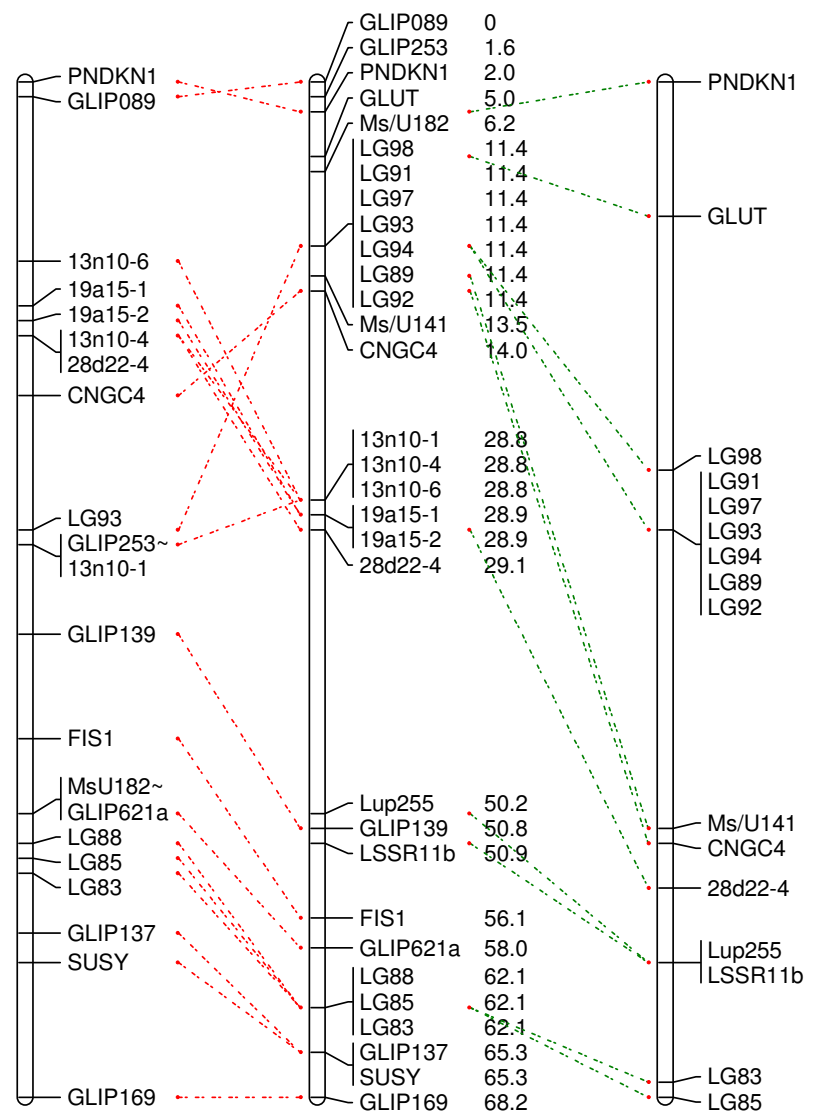

B

FB-2 Mt-1 Len-III

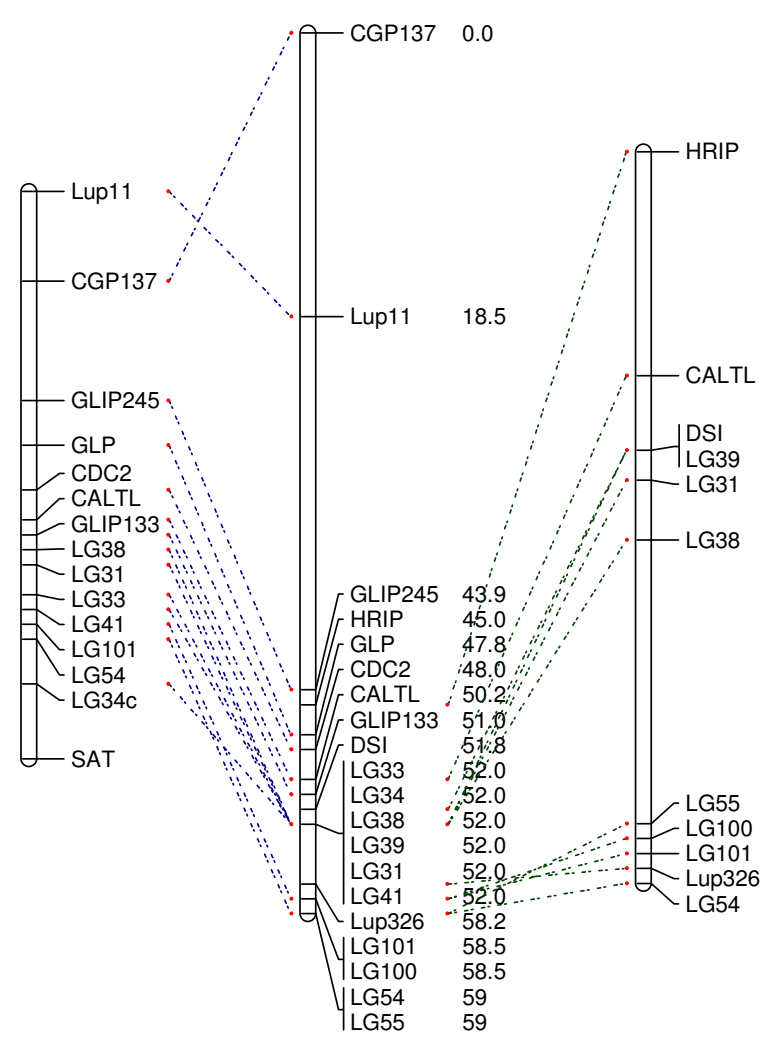

\section{Figure 3}

Evidence of shared macrosynteny between V. faba chromosomes FB-I and FB-2, $L$. culinaris and $M$. truncatula. Common orthologous markers are depicted by dashed lines and marker distances are provided in centi-Morgans for $M$. truncatula only. The figures exclude markers that could not be positioned in the $M$. truncatula psuedogenome. A indicates markers that map distally in the corresponding $M$. truncatula chromosome relative to faba bean, and markers suffixed a, b or c denotes derivation from primer pairs that produced multiple PCR products.

were found to be relatively consistent between $M$. truncatula and other legume species i.e. high conservation of $M$. truncatula chromosomes 1, 5 and 8; moderate conservation in the M. truncatula chromosomes 2, 3, 4 and 7 and lowest conservation in the M. truncatula chromosome 6 (Figures 3, 4 and [39]). As described above, no homology was identified with M. truncatula chromosome 6 in this study. The alignment of this faba bean map with lentil and the current $M$. truncatula genome based on M. truncatula genome assembly Mt2.0 is slightly different to that based on an earlier assembly [15]. The changes can be observed in Figure 3B where orthologous markers which were syntenic to $M$. truncatula chromosome 6 in lentil are now co-linear with $M$. truncatula chromosome 1 in common with faba bean.

Genome studies have demonstrated different factors are responsible for genome size variation and speciation. These include ancient polyploidisation events in the case of the Brassicas [40]; segmental or region-specific duplication [41]; and genetic rearrangements, transposable element amplification, or combination of different genome modifications [42]. Large scale rearrangements, duplications, or polyploidisation were not apparent in this study, 
A

FB-3

Mt-4

Len-I

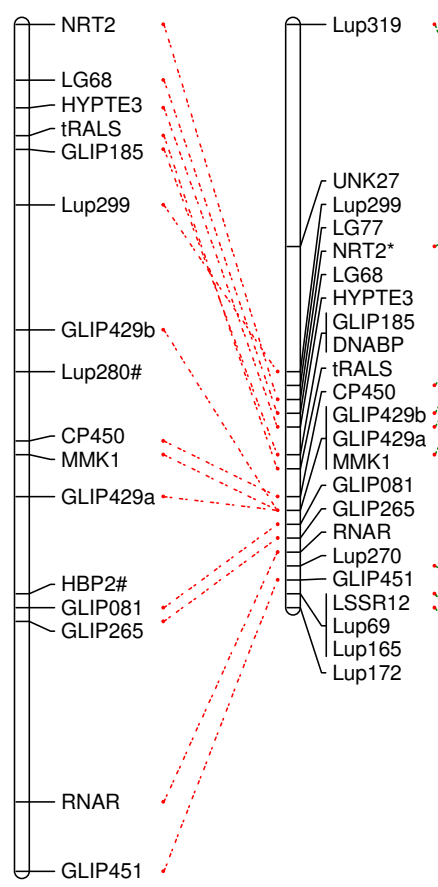

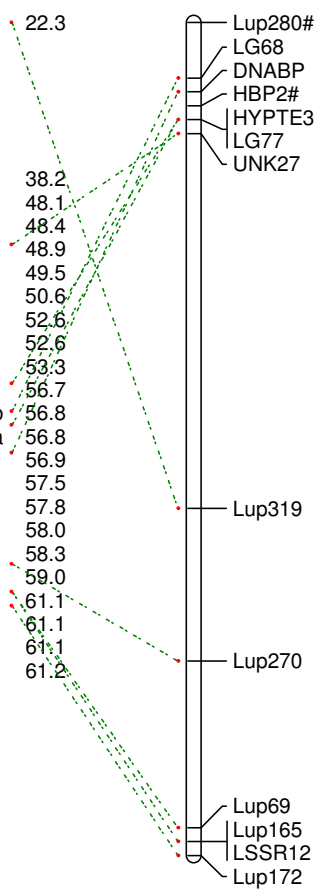

B

FB-5 Mt-3 Len-VII

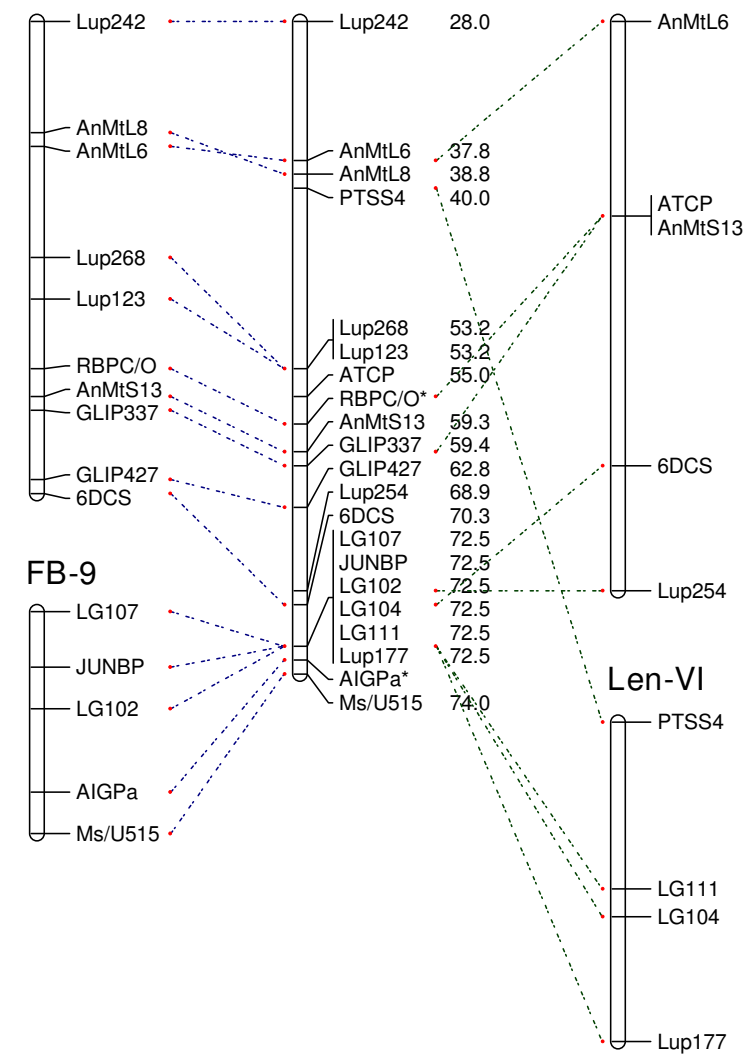

\section{Figure 4}

Evidence of shared macrosynteny between V. faba chromosomes FB-3 and FB-5, L. culinaris and M. truncatula. Common orthologous markers are depicted by dashed lines and marker distances are provided in centi-Morgans for $M$. truncatula only. The figures exclude markers that could not be positioned in the $M$. truncatula psuedogenome. Markers highlighted * were previously mapped [18] but not positioned in the $M$. truncatula psuedogenome. \# indicates markers orthologous between lentil and faba bean but unmapped in $M$. truncatula and markers suffixed a, b or c denotes derivation from primer pairs that produced multiple PCR products.

possibly as a result of the focus on single locus markers, however differences in non-coding repetitive DNA or transposable elements provide a possible explanation for the large differences in genome size. Retroelements are known to account for substantial proportions of these Viceae genomes as shown by extensive studies in pea, for example [43,44], and more recently Vicia $[45,46]$. Local genic rearrangements similar to that in found in the grasses (duplications, translocations, and insertions or deletions) may explain multiple PCR amplicons $[19,20]$.
The shared macrosynteny among the three species demonstrated here and even higher level of homology between $L$. culinaris and $V$. faba will undoubtedly facilitate the identification of markers closely linked to traits of interest in $V$. faba. Alignment of this map with existing faba bean maps containing important traits with polymorphic SSR markers and/or markers developed in this study, coupled with cross-reference to the abundant genetic information from the Medicago genome sequencing and extensive EST libraries available for the model leg- 
ume species, will undoubtedly assist this process. As the parental line Vf6 has been used in a number of genetic and QTL mapping projects $[6,7,9]$, this map can serve as a central reference map. This study has provided a number of significant outcomes for faba bean genomics and legume genomics in general.

\section{Authors' contributions}

SE and RPO designed the research. HTTP and SE wrote the manuscript. HTTP, SE and MG performed marker polymorphism discovery and population genotyping in Perth. $\mathrm{JH}$ assisted with informatics procedures. AMT, CMA and SC-I were involved in developing recombinant inbred lines and marker polymorphism discovery of GLIP markers in Córdoba. All authors read and approved the final manuscript.

\section{Additional material}

\section{Additional file 1}

Supplementary table 1. Orthologous PCR markers developed in this study and genetically mapped in a $F_{6}$ faba bean population between lines VfG and Vf27.

Click here for file

[http://www.biomedcentral.com/content/supplementary/14712164-9-380-S1.doc]

\section{Acknowledgements}

This research was supported by an ARC Linkage project LP045487I, the New South Wales Departments of Primary Industry and the GLIP project FP6-2002-FOOD-I-506223.

\section{References}

I. Michaelis A, Rieger R: Strukturheterozygotie bei Vicia faba. Zuchter 1959, 29:354-361.

2. Sjodin J: Induced morphological variation in Vicia faba $\mathbf{L}$. Hereditas 1971, 67:155-180.

3. Bond DA, Poulsen MH: Pollination. In The Faba Bean Edited by: Hebblethwaite PD. Butterworths; 1983:77-I0I.

4. Van de Ven WTG, Waugh R, Duncan N, Ramsay G, Dow N, Powell W: Development of a genetic linkage map in Vicia faba using molecular and biochemical techniques. Aspects Appl Biol 1991, 27:49-54.

5. Torres AM, Weeden NF, Martín A: Linkage among isozyme, RFLP and RAPD markers in Vicia faba. Theor Appl Genet 1993 85(8):937-945.

6. Satovic Z, Torres AM, Cubero Jl: Genetic mapping of new morphological, isozyme and RAPD markers in Vicia faba L. using trisomics. Theor Appl Genet 1996, 93(7): I I30- I I 38.

7. Vaz Patto MC, Torres AM, Koblizkova A, Macas J, Cubero Jl: Development of a genetic composite map of Vicia faba using F2 populations derived from trisomic plants. Theor Appl Genet 1999, 98(5):736-743.

8. Román B, Torres AM, Rubiales D, Cubero Jl, Satovic Z: Mapping of quantitative trait loci controlling broomrape (Orobanche crenata Forsk.) resistance in faba bean (Vicia faba L.). Genome 2002, 45: 1057-1063.

9. Román B, Satovic Z, Pozarkova D, Macas J, Dolezel J, Cubero J Torres AM: Development of a composite map in Vicia faba, breeding applications and future prospects. Theor Appl Genet 2004, I 08(6): 1079-1088.
10. Avila CM, Satovic Z, Sillero JC, Rubiales D, Moreno MT, Torres AM: Isolate and organ-specific QTLs for ascochyta blight resistance in faba bean (Vicia faba L). Theor Appl Genet 2004, I08(6): $107 \mid-1078$

I I. Choi HK, Kim D, Uhm T, Limpens E, Lim H, Mun JH, Kalo P, Penmetsa RV, Seres A, Kulikova O, Roe BA, Bisseling T, Kiss GB, Cook DR: A sequence-based genetic map of Medicago truncatula and comparison of marker colinearity with M. sativa. Genetics 2004, I 66(3): | 463-I502.

12. Choi HK, Mun JH, Kim DJ, Zhu H, Baek JM, Mudge J, Roe B, Ellis N, Doyle J, Kiss GB, Young ND, Cook DR: Estimating genome conservation between crop and model legume species. PNAS 2004, I 0 I(43): I 5289-I5294.

13. Nelson M, Phan H, Ellwood S, Moolhuijzen P, Hane J, Williams A, O'Lone C, Fosu-Nyarko J, Scobie M, Cakir M, Jones M, Bellgard M, Ksiazkiewicz M, Wolko B, Barker S, Oliver R, Cowling W: The first gene-based map of Lupinus angustifolius L.-location of domestication genes and conserved synteny with Medicago truncatula. Theor Appl Genet 2006, I I 3(2):225-238.

14. Phan HTT, Ellwood SR, Adhikari K, Nelson MN, Oliver RP: The first genetic and comparative map of white lupin (Lupinus albus L.): Identification of QTLs for anthracnose resistance and flowering time, and a locus for alkaloid content. DNA Res 2007, I 4(2):59-70

15. Phan HTT, Ellwood SR, Hane JK, Ford R, Materne M, Oliver RP: Extensive macrosynteny between Medicago truncatula and Lens culinaris ssp. culinaris. Theor Appl Genet 2007, I | 4(3):549-558.

16. Zhu H, Choi HK, Cook DR, Shoemaker RC: Bridging model and crop legumes through comparative genomics. Plant Physiology 2005, I37(4): I I89-1196.

17. Aubert G, Morin J, Jacquin F, Loridon K, Quillet M, Petit A, Rameau C, Lejeune-Henaut I, Huguet T, Burstin J: Functional mapping in pea, as an aid to the candidate gene selection and for investigating synteny with the model legume Medicago truncatula. Theor Appl Genet 2006, I I 2(6): I024-104I.

18. Choi HK, Luckow MA, Doyle J, Cook DR: Development of nuclear gene-derived molecular markers linked to legume genetic maps. Mol Genet Genomics 2006, 276(I):56-70.

19. Bennetzen JL: Comparative sequence analysis of plant nuclear genomes: Microcolinearity and its many exceptions. Plant Cell 2000, I 2(7): $1021-1030$.

20. Devos KM, Gale MD: Genome relationships: The grass model in current research. Plant Cell 2000, I 2(5):637-646.

21. Torres AM, Satovic Z, Canovas J, Cobos S, Cubero Jl: Genetics and mapping of new isozyme loci in Vicia faba $L$ using trisomics. Theor Appl Genet 1995, 9 I(5):783-789.

22. Ellwood SR, D'Souza NK, Kamphuis LG, Burgess TI, Nair RM, Oliver RP: SSR analysis of the Medicago truncatula SARDI core collection reveals substantial diversity and unusual genotype dispersal throughout the Mediterranean basin. Theor Appl Genet 2006, I I 2(5):977-983.

23. MultiQTL - the best QTL mapping software [http://www.mul tiqtl.com/

24. MapChart [http://www.biometris.wur.nl/uk/Software/MapChart/]

25. Medicago truncatula sequencing resources [http://www.med icago.org/genome/]

26. Grid Map [http://cbr.jic.ac.uk/dicks/software/Grid Map/index.html]

27. Purcell S: Statistical Methods in Quantitative Genetics. In Behavioural Genetics 4th edition. Edited by: Plomin PR, DeFries PJ, McClearn PG, McGuffin PP. New York, Worth Publishers; 200I.

28. Arumuganathan K, Earle ED: Nuclear DNA content of some important plant species. Plant Mol Biol 1991, 9:208-218.

29. Weeden NF, Muehlbauer FJ, Ladizinsky G: Extensive conservation of linkage relationships between pea and lentil genetic maps. J Hered 1992, 83(2): I23-I29.

30. Kalo P, Seres A, Taylor S, Jakab J, Kevei Z, Kereszt A, Endre G, Ellis T, Kiss G: Comparative mapping between Medicago sativa and Pisum sativum. Mol Genet Genomics 2004, 272(3):235-246.

31. Gualtieri G, Kulikova O, Limpens E, Kim DJ, Cook DR, Bisseling T, Geurts R: Microsynteny between pea and Medicago truncatula in the SYM2 region. Plant Mol Biol 2002, 50(2):225-235.

32. Stracke S, Sato S, Sandal N, Koyama M, Kaneko T, Tabata S, Parniske $M$ : Exploitation of colinear relationships between the genomes of Lotus japonicus, Pisum sativum and Arabidopsis 
thaliana, for positional cloning of a legume symbiosis gene. Theor Appl Genet 2004, 108(3):442-449.

33. Mudge J, Cannon S, Kalo P, Oldroyd G, Roe B, Town C, Young N: Highly syntenic regions in the genomes of soybean, Medicago truncatula, and Arabidopsis thaliana. BMC Plant Biol 2005, 5(I): 15 .

34. Cannon SB, Sterck L, Rombauts S, Sato S, Cheung F, Gouzy J, Wang $X$, Mudge J, Vasdewani J, Schiex T, Spannagl M, Monaghan E, Nicholson C, Humphray SJ, Schoof H, Mayer KFX, Rogers J, Quetier F, Oldroyd GE, Debelle F, Cook DR, Retzel EF, Roe BA, Town CD, Tabata $S$, Van de Peer Y, Young ND: Legume genome evolution viewed through the Medicago truncatula and Lotus japonicus genomes. Proceedings of the National Academy of Sciences 2006, 103(40): | 4959-| 4964 .

35. Zhu H, Kim DJ, Baek JM, Choi HK, Ellis LC, Kuester H, McCombie WR, Peng HM, Cook DR: Syntenic relationships between Medicago truncatula and Arabidopsis reveal extensive divergence of genome organization. Plant Physiology 2003, 131(3): $1018-1026$.

36. Doyle J], Luckow MA: The rest of the iceberg. Legume diversity and evolution in a phylogenetic context. Plant Physiology 2003, I3 I(3):900-910.

37. Kulikova O, Gualtieri G, Geurts R, Kim DJ, Cook D, Huguet T, de Jong JH, Fransz PF, Bisseling T: Integration of the FISH pachytene and genetic maps of Medicago truncatula. Plant Journal 200I, 27(1):49-58

38. Zhu H, Cannon SB, Young ND, Cook DR: Phylogeny and genomic organization of the TIR and non-TIR NBS-LRR resistance gene family in Medicago truncatula. Mol Plant Microbe Interact 2002, I 5(6):529-359.

39. Phan HTT, Ellwood SR, Ford R, Thomas S, Oliver R: Differences in syntenic complexity between Medicago truncatula with Lens culinaris and Lupinus albus. Funct Plant Biol 2006, 33(8):775-782

40. Lagercrantz $U$, Lydiate $D$ : Comparative genome mapping in Brassica. Genetics 1996, 144(4):1903-1910.

41. Lawton-Rauh A: Evolutionary dynamics of duplicated genes in plants. Molecular Phylogenetics and Evolution 2003, 29(3):396-409.

42. Bennetzen JL: Patterns in grass genome evolution. Curr Opin Plant Biol 2007, I0(2): 176-181.

43. Macas J, Neumann P, Navratilova A: Repetitive DNA in the pea (Pisum sativum L.) genome: comprehensive characterization using 454 sequencing and comparison to soybean and Medicago truncatula. BMC Genomics 2007, 8(I):427.

44. Murray MG, Peters DL, Thompson WF: Ancient repeated sequences in the pea and mung bean genomes and implications for genome evolution. Journal of Molecular Evolution 198I, I 7(I):31-42.

45. Neumann P, Koblizkova A, Navratilova A, Macas J: Significant expansion of Vicia pannonica genome size mediated by amplification of a single type of giant retroelement. Genetics 2006, I 73(2): 1047-1056.

46. Pearce SR, Harrison G, Li D, Heslop-Harrison JS, Kumar A, A.J. F: The Tyl-copia group retrotransposons in Vicia species: copy number, sequence heterogeneity and chromosomal location. Mol Gen Genet 1996, 250:305-315.
Publish with BioMed Central and every scientist can read your work free of charge

"BioMed Central will be the most significant development for disseminating the results of biomedical research in our lifetime. "

Sir Paul Nurse, Cancer Research UK

Your research papers will be:

- available free of charge to the entire biomedical community

- peer reviewed and published immediately upon acceptance

- cited in PubMed and archived on PubMed Central

- yours - you keep the copyright
BioMedcentral 